\title{
Serum proteome analysis for profiling protein markers associated with carcinogenesis and lymph node metastasis in nasopharyngeal carcinoma
}

\author{
Qiulin Liao $\cdot$ Liang Zhao $\cdot$ Xiaodong Chen $\cdot$ \\ Yongjian Deng $\cdot$ Yanqing Ding
}

Received: 8 December 2007 / Accepted: 16 February 2008/Published online: 21 March 2008

(C) The Author(s) 2008

\begin{abstract}
Nasopharyngeal carcinoma (NPC), one of the most common cancers in population with Chinese or Asian progeny, poses a serious health problem for southern China. It is unfortunate that most NPC victims have had lymph node metastasis (LNM) when first diagnosed. We believe that the $2 \mathrm{D}$ based serum proteome analysis can be useful in discovering new biomarkers that may aid in the diagnosis and therapy of NPC patients. To filter the tumor specific antigen markers of NPC, sera from 42 healthy volunteers, 27 non-LNM NPC patients and 37 LNM NPC patients were selected for screening study using $2 \mathrm{D}$ combined with MS. Pretreatment strategy, including sonication, albumin and immunoglobulin $\mathrm{G}$ ( $\mathrm{IgG}$ ) depletion, was adopted for screening differentially expressed proteins of low abundance in serum. By 2D image analysis and MALDI-TOF-MS identification, twenty-three protein spots
\end{abstract}

Qiulin Liao and Liang Zhao authors contributed equally.

Q. Liao $\cdot$ L. Zhao $\cdot$ Y. Deng $\cdot$ Y. Ding

Department of Pathology, School of Basic Medical Sciences,

Southern Medical University, Guangzhou, China

Q. Liao $\cdot$ L. Zhao · Y. Ding

Key Laboratory of Functional Proteomics and Molecular Tumor Pathology of Guangdong Province, Southern Medical

University, Guangzhou, China

L. Zhao $\cdot$ Y. Deng $\cdot$ Y. Ding $(\bowtie)$

Department of Pathology, Nanfang Hospital, Southern Medical

University, Guangzhou 510515, China

e-mail: dyq@fimmu.com

X. Chen

Department of Pathology, General Hospital of Guangzhou

Military Command, Guangzhou, China were differentially expressed. Three of them were further validated in the sera using enzyme-linked immunosorbent assay (ELISA). Our research demonstrates that HSP70, sICAM-1 and SAA, confirmed with ELISA at sera and immunohistochemistry, are potential NPC metastasis-specific serum biomarkers which may be of great underlying significance in clinical detection and management of NPC.

Keywords Nasopharyngeal carcinoma .

Serum proteome $\cdot$ Carcinogenesis $\cdot$ Lymph node metastasis

$\begin{array}{ll}\begin{array}{l}\text { Abbreviations } \\ \text { NPC }\end{array} & \begin{array}{l}\text { Nasopharyngeal carcinoma } \\ \text { Two-dimensional electorphoresis } \\ \text { MALDI-TOF-MS } \\ \text { Matrix-assisted laser desorption/ } \\ \text { ionization-time of flight-mass } \\ \text { spectrometry }\end{array} \\ \text { LNM } & \text { Lymph node metastasis } \\ \text { ICAM-1 } & \text { Intercellular adhesion molecular-1 } \\ \text { HSP70 } & \text { Heat shock protein 70 } \\ \text { SAA } & \text { Serum amyloid A1 protein } \\ \text { ELISA } & \text { Enzyme-linked immunosorbent assay } \\ \text { IHC } & \text { Immunohistochemistry }\end{array}$

\section{Introduction}

Nasopharyngeal carcinoma (NPC) is a rare malignancy in most parts of the world, though it is highly prevalent in Southern Asia, where the incidence is about a 100-fold higher than in other populations. It is one of the most confusing, commonly misdiagnosed and poorly understood diseases. Previous studies show that the cancer is an Epstein-Barr virus-associated malignancy with a 
remarkable racial and geographical distribution. The etiology of NPC is thought to be associated with a complex interaction of genetic, viral, environmental and dietary factors. Thanks to the advancements in genomics, proteomics and bioinformatics in recent decades, the etiology, carcinogenesis and progression of the disease is better understood. Research into these components may unravel the pathways in NPC development and potentially decipher the molecular characteristics of the malignancy $[1,2]$. NPC is an insidious tumor and is usually at the stage of metastasis involving lymph nodes or other organs before it can be found. Thus early and accurate diagnosis is very important for therapy and prognosis of NPC patients. Unfortunately, no effective method of accurately diagnosing new-onset NPC is available now. We presume if specific serum biomarkers associated with NPC metastasis can be identified on the basis of advancements in genomics, proteomics and bioinformatics, an approach to the early detection and monitoring of NPC may be found.

2D comparative proteome analysis is a new technology for the separation and identification of disease-specific proteins, and it has been applied successfully to screen potential biomarkers for NPC in cell lines and tumor tissues [3-8]. In our previous studies, we employed proteomic techniques to study protein changes of CNE2, a poorly differentiated squamous carcinoma cell line of human NPC cells, induced by $12-O$-Tetradecanoyl-phorbol-13-acetate (TPA). It is likely that TPA promotes NPC in necessary cooperation with EBV, or that it may function as an antiproliferative or differentiative revulsant in noninitiated cells [4]. However, if a marker can be detected only in surgical specimens, its clinical significance is limited, especially for early screening or diagnosis. Recently, Saeid R. et al. reported their pioneering work on NPC serum analysis by $2 \mathrm{D}$ without any pretreatment, revealing the enhanced expression of relatively abundant proteins as ceruloplasmin (CPL) [9]. In order to find relatively lowabundant serum proteins which may be more valuable in predicting NPC progression, we pretreated serum with sonication, albumin and $\mathrm{IgG}$ depletion before $2 \mathrm{D}$ analysis. By comparing 2D image analyses for healthy volunteers, non-LNM NPC and LNM NPC patients, we may identify the differentially expressed proteins so that specific serum biomarkers associated with NPC metastasis can be found.

\section{Materials and methods}

\section{Subjects}

Serum samples from 42 healthy volunteers and 64 NPC patients were available for comparative proteomic analysis. Samples from NPC patients were obtained before any clinical treatment. All the patients had a nasopharyngeal biopsy and NPC was confirmed by two independent pathologists unaware of the patient's condition. Careful medical examinations and CT scan determined non-LNM cases and LNM cases in the NPC patients. Clinical data of all the subjects for 2D and ELISA are shown in Table 1. In the screening study, serum samples from the same group were pooled to smooth intrinsic individual differences and enhance common characteristic traits only related to disease status [10], aliquoted, and stored at $-80^{\circ} \mathrm{C}$ before analysis. In the validation study, 26 of the patients received a mean of 17.8 months of follow-up (range, 6-22 months) after radiotherapy and/or chemotherapy. Six of the followed-up patients died of NPC, and the other survived the follow-up period.

\section{Depletion of high-abundance proteins}

Sigma-Aldrich ProteoPrep ${ }^{\circledR}$ Immunoaffinity Albumin and IgG Depletion Kit was used for depletion of proteins, albumin and IgGs, allowing visualization of co-migrating proteins with albumin and IgG on a $2 \mathrm{D}$ gel and also higher sample loads for improved visualization of lower abundance proteins. A total of $30 \mu \mathrm{l}$ of serum was diluted with $100 \mu \mathrm{l}$ of equilibration buffer from the depletion kit (Sigma) and sonicated using four ultrasonic bursts of $15 \mathrm{~s}$ each. Between sonications, the samples were chilled on ice. Then serum albumin and IgG was depleted according to the manufacturer's instructions. After collection of the bound proteins, the majority $(>95 \%)$ of the unbound proteins were left in the depleted serum sample. Modified Bradford assay was used to measure the protein concentrations of all serum samples [11].

\section{D analysis}

The Immobiline Dry strip (pH 4-7, length $17 \mathrm{~cm}$, Bio-Rad) was rehydrated with $600 \mathrm{mg}$ protein in $350 \mathrm{ml}$ rehydration buffer containing $7 \mathrm{M}$ urea, $2 \mathrm{M}$ thiourea, 4\% CHAPS, $65 \mathrm{mM}$ DTT, $5 \mathrm{mM}$ tributylphosphine, 1\% IPG buffer and $0.002 \%$ bromophenol blue for $14 \mathrm{~h}$ at room temperature. IEF was performed using Protean IEF cell (Bio-Rad, Hercules, CA, USA) with a total of $70 \mathrm{kVh}$. Then the strip was subjected to two-step equilibration in equilibration buffer containing $6 \mathrm{M}$ urea, 30\% glycerol, 2\% SDS and $50 \mathrm{mM}$ Tris- $\mathrm{HCl}$ (pH 6.8) with $1 \% \mathrm{w} / \mathrm{v}$ DTT for the first step, and $2.5 \% \mathrm{w} / \mathrm{v}$ iodoacetamide for the second step. The second-dimensional SDS-PAGE gel $(13 \% \mathrm{~T}, 2.7 \% \mathrm{C}$, and $20 \times 20 \times 1 \mathrm{~mm}^{3}$ ) was carried out using a Protean II xi 2D cell (Bio-Rad) according to the following procedure: $30 \mathrm{~min}$ at a constant current of $12 \mathrm{~mA}$ followed by $24 \mathrm{~mA}$ per gel until the bromophenol blue front reached the bottom of the gel. Subsequently the gels were stained with 
Table 1 Serum samples in the study

\begin{tabular}{|c|c|c|c|c|c|c|}
\hline & \multicolumn{3}{|c|}{ Samples for 2-DE } & \multicolumn{3}{|c|}{ Samples for ELISA } \\
\hline & Healthy & NPC & & Healthy & NPC & \\
\hline Lymph node status & l & Negative & Positive & l & Negative & Positive \\
\hline Number & 42 & 27 & 37 & 30 & 27 & 30 \\
\hline Gender (Male/Female) & $22 / 20$ & $21 / 6$ & $23 / 14$ & $15 / 15$ & $21 / 6$ & $20 / 10$ \\
\hline Age $( \pm$ SD $)$ & $42 \pm 7.9$ & $43 \pm 10.9$ & $50.5 \pm 11.7$ & $42.5 \pm 8.9$ & $43 \pm 10.9$ & $47.6 \pm 10.2$ \\
\hline
\end{tabular}

MS accommodated silver staining [12]. 2D of each sample was run in triplicate to minimize run-to-run variation. The silver-stained 2D gel were scanned using a Power-Look 1100 imaging scanner (Umax, Dallas, TX, USA) and analyzed using PDQuest 7.1 software package (Bio-Rad).

In-gel enzymatic digestion

Protein spots were excised from gel with an operating knife blade, destained twice with $30 \mathrm{mM}$ potassium ferricyanide and $100 \mathrm{mM}$ sodium thiosulfate $(1: 1 \mathrm{v} / \mathrm{v})$ and then equilibrated in $50 \mathrm{mM} \mathrm{NH} \mathrm{HCO}_{3}$ to $\mathrm{pH}$ 8.0. After dehydrating with $\mathrm{ACN}$ and drying in $\mathrm{N}_{2}$ at $37^{\circ} \mathrm{C}$ for $20 \mathrm{~min}$, the gel pieces were rehydrated in $15 \mathrm{ml}$ trypsin solution $(10 \mu \mathrm{g} / \mathrm{ml}$ in $25 \mathrm{mM} \mathrm{NH}_{4} \mathrm{HCO}_{3}$ ) at $4^{\circ} \mathrm{C}$ for 30 min and incubated at $37^{\circ} \mathrm{C}$ overnight. Peptides were extracted twice using $0.1 \%$ TFA in 50\% CAN and dried with $\mathrm{N}_{2}$.

\section{MALDI-TOF-MS identification}

The peptide mixtures were solubilized with $0.5 \%$ TFA, with saturated $\alpha$-cyano-4-hydroxy-trans-cinnamic (CHCA) solution in $0.1 \% \mathrm{TFA} / 50 \%$ acetonitrile as the matrix and analyzed using M@LDI R (Micromass, Manchester, UK). Mass spectra were externally calibrated with lock mass 2,465.199 $\mathrm{Da}$ and internally calibrated with autodigested peaks of trypsin (MH+: 2,211.105 Da).

Protein identification and database searching

Protein identification using peptide mass fingerprinting (PMF) was performed by the MASCOT search engine (http://www.matrixscience.com/, MatrixSicence Ltd., London, UK) against the MSDB protein database. The errors in peptide masses were in the range of $25 \mathrm{ppm}$. One missed tryptic cleavage site per peptide was allowed during the search. Proteins matching more than four peptides and with a MASCOT score higher than 64 were considered significant $(P<0.05)$. Carboamidomethylation of cysteine was selected as the static modification and oxidation of methionine as the differential modification. Protein identification results were filtered with peakErazor software.
Enzyme-linked immunosorbent assay (ELISA) confirmation

ELISAs were conducted to confirm the protein identification and differential expression of sICAM-1, SAA and HSP70 in sera from the three groups. Measurements were done by commercially available ELISA kits (StressXpress Hsp70 ELISA Kit: EKS-700B, Stressgen Biotechnologies, Victoria; High sensitivity sICAM-1 ELISA Kit: BMS241, Bender Medsystems Company, Australian; Human SAA ELISA Kit: EL10015, YES Biotech Laboratories Ltd, Canada), in accordance with the manufacturer's instructions. All sera were stored at $-80^{\circ} \mathrm{C}$ before they were measured. Both standards and samples were run in duplicate. The main protocols were as follows: monoclonal coating antibody was adsorbed onto microwells; target protein present in the sample or standard bound to antibodies was adsorbed to the microwells; second antibody was added and bound to target protein captured by the first antibody; following incubation unbound enzyme was removed during a wash step; a color reaction was formed and absorbance was measured at $450 \mathrm{~nm}$. The standard curve was used to determine the concentration of target protein in an unknown sample.

Immunohistochemistry (IHC) assay

The previous studies showed that sICAM-1 in serum could be released by membrane-associated ICAM-1 of cancer cell $[13,14]$. However, SAA is synthesized and secreted into serum by hepatocytes in the liver during the acute phase $[15,16]$. In the present study, therefore, expressions of only HSP70 and ICAM-1 were detected in tissue by IHC assay. Three-micrometer sections of paraffin-embedded tissues were cut for a prior antigen retrieval step in boiling $10 \mathrm{mM}$ citrate buffer $\mathrm{pH} 6$ for $20 \mathrm{~min}$. The fixed tissues were subjected to immunostaining using an ultrasensitive S-P technique (MaiXin, China). Briefly, the slides were incubated overnight at $4{ }^{\circ} \mathrm{C}$ with goat anti-ICAM and antiHSP70 polyclonal antibody (1:200) (Wuhan Boster Biological Technology Co., Ltd., China). The concentrations of the primary antibodies used have been optimized previously. After washing with PBS three times, they were 
treated with biotin-conjugated second antibody before adding streptavidin-peroxidase. For color reaction, diaminobenzidine (DAB) was used. All series included positive controls. For negative controls, the antibody was replaced by PBS. To evaluate the expression, the cellular localization of immunoreactivity was determined and scored for both intensity (negative, weak, moderate and strong) and proportion $(5-25,26-50,51-75$ and $76-100 \%)$ of stained cells. To allow comparison of immunostaining with pathological stage and metastasis for each cancer, integer values were assigned to the scores of intensity $(0-3)$ and proportion of tumor cells stained (0-4). If the evaluations did not agree, the specimens were reevaluated and then classified according to the assessments given, most frequently, by the observers. The proportion and intensity scores were then added to obtain a total score, which was labeled as one of the four following categories: (a) high positive $(+++)$, total score of 6-7; (b) moderate positive $(++)$, total score of $4-5$; (c) low positive (+), total score of $2-3$; (d) negative (-), total score of $0-2$.

\section{Statistical analysis}

All the analyses performed were descriptive. The serum levels of protein expressions were compared using one-way ANOVA test. Associations between immunohistochemical scores and clinicopathological variables of tissue specimens were evaluated by Fisher's exact test or $\chi^{2}$ test. PDQuest software was used to establish a master gel representing each group [17]. For differential expression of matched gels, protein spots whose intensities were either increased or decreased two-fold or greater were marked and then confirmed by manual inspection of all relevant $2 \mathrm{D}$ gel, not only those included in the matchsets, to ensure consistency. Quantitative analysis was performed using the Student's $t$-test among three groups of gels. All statistical analysis was performed with SPSS 10.0 software and $P$ value $<0.05$ were considered statistically significant.

\section{Results}

Quantitative comparison and identification of protein spots on 2D gels

Among the three groups, we found twenty-three spots significantly altered $(P<0.05)$ or absent/emergent, 13 of which were identified successfully (Fig. 1). The corresponding detailed differential expression patterns are shown in Fig. 2a. Quantitative comparison and MS identification of the 13 differentially expressed proteins are shown in Fig. 2b and summarized in Table 2, respectively. Overall, transferrin (TRF) and transthyretin (TTR) were
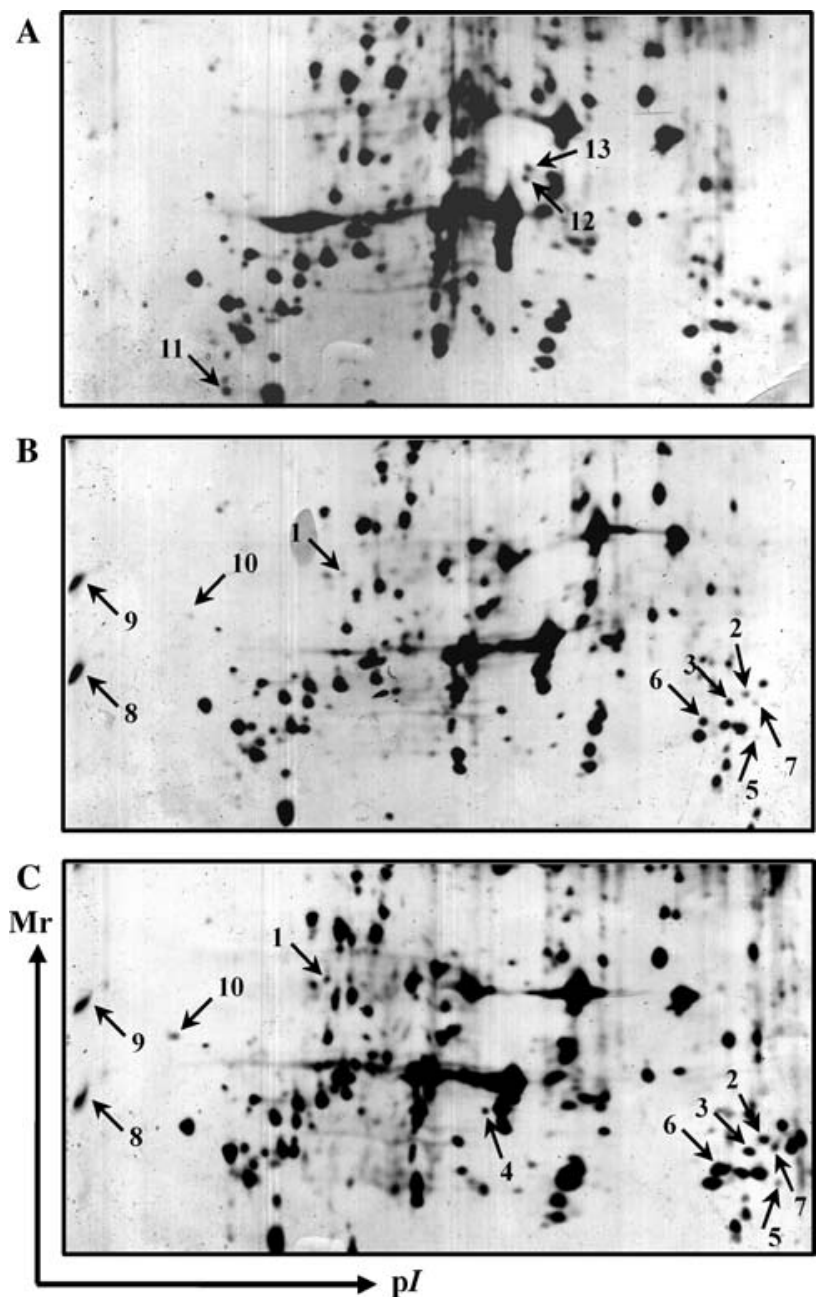

Fig. 1 Representative 2D patterns of albumin and $\operatorname{IgG}$ depleted serum from healthy (a), non-LNM NPC (b) and LNM NPC groups (c). In the 2D images, spots ' $1-10$ ' indicate up-regulation and '11-13' down-regulation in NPC group. Black arrows indicate protein spots that were identified successfully by MS

down-regulated and 12-lipoxygenase (12-LOX), serum amyloid A1 protein precursor (SAA), soluble intercellular adhesion molecule-1 (sICAM-1) and lysine-specific histone demethylase1 (LSD1) were up-regulated in two NPC groups compared with the healthy group. Furthermore, increased expression levels of 12-LOX, sICAM-1 and SAA were observed in LNM NPC as compared with non-LNM NPC. However, heat shock protein 70 (HSP70) and cytochrome P450 (CYP450) were expressed significantly and constantly only in LNM NPC patients. The MALDI-TOFMS mass spectra are shown in Fig. 3.

\section{ELISA confirmation}

Figures 4 and 5 show the ELISA results of sICAM-1, SAA and HSP70 performed in the three groups. There were 
Fig. 2 Detailed 2D patterns of the thirteen differentially expressed proteins among healthy, non-LNM and LNM NPC groups (a). Corresponding gel positions are shown in Fig. 1. Magnified 2D maps demonstrating the different expressions of selected proteins are listed in Table 2. The densitometric analysis of each protein was calculated from nine different gels using PDQuest 7.1 software package (b). Each bar represents the mean \pm S.D. of intensity, with significant differences between groups found by two-tailed student's-test. Note that this panel has a different vertical (y) axis and a break in the axis to accommodate the poor performance of the subject spot No.6. The break region is from 5000 to 6000 . $* P<0.05$, compared with healthy group; $* * P<0.05$, compared with non-LNM NPC group
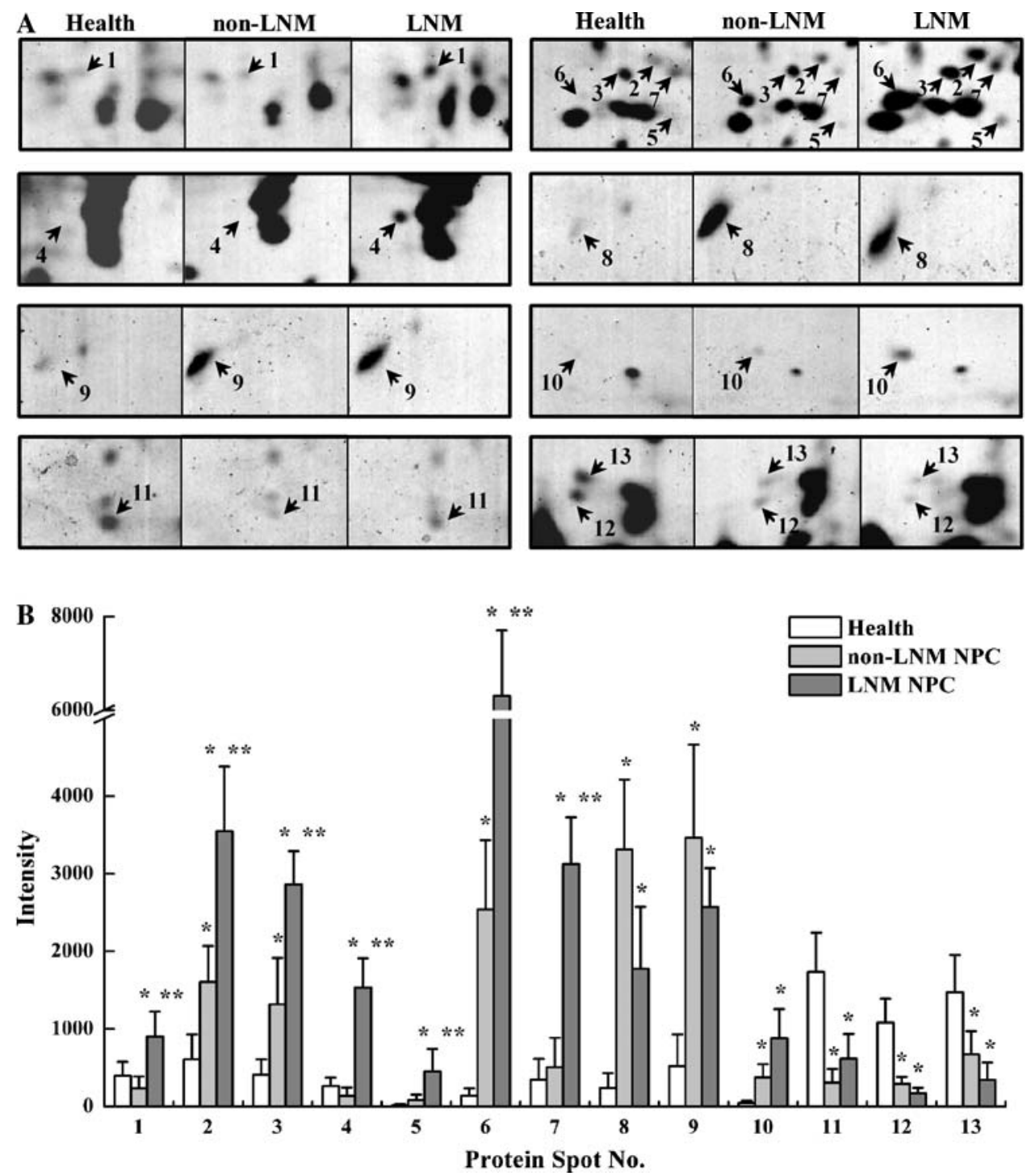

statistically significant differences between health and NPC groups $(P<0.01)$ as well as between non-LNM and LNM NPC groups $(P<0.05)$ (Fig. 4). And with the TNM stage advanced, the serum levels of sICAM-1 and HSP70, were detected significantly elevated, but that of SAA not (Fig. 5). Furthermore, bivariate correlation analysis showed a significant relationship between the serum levels of the three proteins $(P<0.01)$. The follow-up showed that the serum levels of sICAM-1 and HSP70, but not of SAA, were strongly associated with NPC mortality (Student's $t$-test, $P=0.001$, 0.001 and 0.132 , respectively). Our ELISA findings were consistent with results of $2 \mathrm{D}$ and silver-staining.

\section{IHC assay}

In NPC patients, HSP70 and ICAM-1 were observed in tumor cells but not in stromal, endothelial or inflammatory cells. The immunoreactivity was located in both membrane and cytoplasm for ICAM-1 and only in cytoplasm for HSP70 (Fig. 6). The immunoreactivities of HSP70 and ICAM-1 were observed in 37 (64.9\%) and $43(75.4 \%)$ of the 57 cases of NPC, respectively. The correlation of positive rates showing HSP70 and ICAM-1 immunoreactivity with clinicpathological characteristics of the cases is summarized in Table 3. Statistically, positive expression rates of HSP70 and ICAM-1 were significantly correlated with lymph node metastasis (LNM) of NPC. Furthermore, we found that positive expression rates of ICAM-1 (6/6, 100\%) and HSP70 $(5 / 6,83.3 \%)$ were high in the cases that died of NPC during the follow-up period $(P>0.05)$. The results manifested that ICAM-1 and HSP70 expressions were strongly associated with NPC metastasis and mortality, indicating poor prognosis. 
Table 2 Identification results of differentially expressed proteins among healthy volunteers, non-LNM NPC and LNM NPC patients

\begin{tabular}{|c|c|c|c|c|c|c|}
\hline No. $^{a}$ & Protein description & MSDB ID & $\begin{array}{l}\text { Protein } \\
\text { level }^{\mathrm{b}}\end{array}$ & $\begin{array}{l}\text { MASCOT } \\
\text { score }^{c}\end{array}$ & $\begin{array}{l}\text { Sequence } \\
\text { coverage }^{\mathrm{d}}(\%)\end{array}$ & $\begin{array}{l}\text { Theoretical } \\
\mathrm{Mr} / \mathrm{p} I^{\mathrm{e}}\end{array}$ \\
\hline 1 & Ovochymase precursor & Q7RTY7 & $\uparrow$ & 116 & 52 & $124,947 / 8.67$ \\
\hline 2 & Arachidonate 12-lipoxygenase & AAA51587 & $\uparrow$ & 193 & 68 & $75,694 / 5.82$ \\
\hline 3 & sICAM-1 & Q99930 & $\uparrow$ & 112 & 54 & $4270 / 6.40$ \\
\hline 4 & Cytochrome P450 & Q53EX9 & $\uparrow$ & 207 & 57 & $55,635 / 6.83$ \\
\hline 5 & Serum amyloid A1 protein precursor & YLHUS & $\uparrow$ & 170 & 85 & $13,524 / 6.28$ \\
\hline 6 & $\begin{array}{l}\text { Hemoglobin beta subunits are s- } \\
\text { nitrosylated }\end{array}$ & 1BUWB & $\uparrow$ & 207 & 55 & $15,565 / 6.76$ \\
\hline 7 & E1A $10 \mathrm{~S}$ protein & Q9YLA2 & $\uparrow$ & 143 & 69 & $28,493 / 4.09$ \\
\hline 8 & Lysine-specific histone demethylase 1 & O60341 & $\uparrow$ & 172 & 58 & $93,358 / 6.11$ \\
\hline 9 & KIAA1622 protein & Q9HCF0 & $\uparrow$ & 78 & 61 & $102,351 / 8.42$ \\
\hline 10 & Heat shock $70 \mathrm{kDa}$ protein (HSP70) & Q6G1F9 & $\uparrow$ & 157 & 53 & $68,161 / 4.88$ \\
\hline 11 & Transferrin & Q9NQB8 & $\downarrow$ & 167 & 67 & $77,050 / 6.81$ \\
\hline 12 & UPF0366 protein C11orf67 & AAD40378 & $\downarrow$ & 104 & 58 & $12,798 / 8.58$ \\
\hline 13 & Transthyretin & AAA61181 & $\downarrow$ & 87 & 69 & $12,836 / 5.35$ \\
\hline
\end{tabular}

${ }^{a}$ The numbers indicate the spot positions in 2D gel as shown in Figs. 1 and 2

b $\uparrow$, up-regulation in NPC patients; $\downarrow$, down-regulation in NPC patients

c By MALDI-TOF MS analysis

${ }^{\mathrm{d}}$ Calculated by amino acid count

${ }^{\text {e }}$ Calculated from the database entry without any processing

\section{Discussion}

Serum is a complex body fluid, containing a large diversity of proteins. More than 10,000 different proteins are present in the human serum and many of them are secreted or shed by cells during different physiology or pathology processes [18]. Consequently, proteomics has raised great expectations for the discovery of biomarkers to improve diagnosis or classification of a wide range of diseases, including cancers [19]. Serum is expected to be an excellent source of protein biomarkers because it circulates through, or comes in contact with, all tissues. During this contact it is likely to pick up proteins secreted or shed by tissues, which has recently been tested and confirmed [20]. However, serum has been termed as the most complex human proteome [21] with considerable differences in the concentrations of individual proteins, ranging from several milligrams to less than one pictogram per milliliter [22]. Another analytical challenge for biomarker discovery arises from the high variability in the concentration and state of modification of some human plasma proteins between different individuals [23]. Despite these limitations, human serum holds immense diagnostic potential. In the last decade, several large-scale projects have been initiated, aimed at characterizing the human plasma/serum proteome.

In the mean time, several serum proteomic studies on NPC have been reported. Cho et al. performed protein chip profiling analysis with surface-enhanced laser desorption ionization time-of-flight mass spectrometry (SELDI-TOFMS) technology on sera from NPC patients and demonstrated that SAA may be a potentially usefully biomarker for NPC [24]. However, the technology for discovery of new cancer biomarkers has recently been questioned for its flaws, such as its qualitative nature, high identification error rate, poor reproducibility and nonspecific absorption matrices [25-27]. 2D-based comparative proteome analysis, though a new technology for the separation and identification of disease-specific proteins, has been applied successfully to screen potential biomarkers for NPC in cell lines and tumor tissues [3-8].

Recently, Saeid et al. reported their pioneering work on NPC serum analysis by $2 \mathrm{D}$, revealing the enhanced expression of such relatively abundant proteins as ceruloplasmin (CPL) [9]. However, in 2D study, abundant proteins, such as albumin and $\operatorname{IgG}$, that account for approximately $60-97 \%$ of the total serum proteins [28], mask other proteins that migrate to the surrounding areas and limit the loading amount of serum. As albumin and IgG are known to function as carriers and transporters of important proteins such as hormones, cytokines, and lipoproteins within the blood [29-31], the depletion of these two highly abundant proteins may result in the loss of potentially important proteins bound to them at the same time. In order to release those adsorbed or bound proteins, 
Fig. 3 PMF of protein spots No. 3, 5 and 10, respectively, representing sICAM-1 (panel A), SAA (panel B), and HSP70 (panel C), which were expressed differentially between the groups of non-LNM and LNM NPC (MASCOT scores are 65, 85 and 78 , respectively, $P<0.05$ )
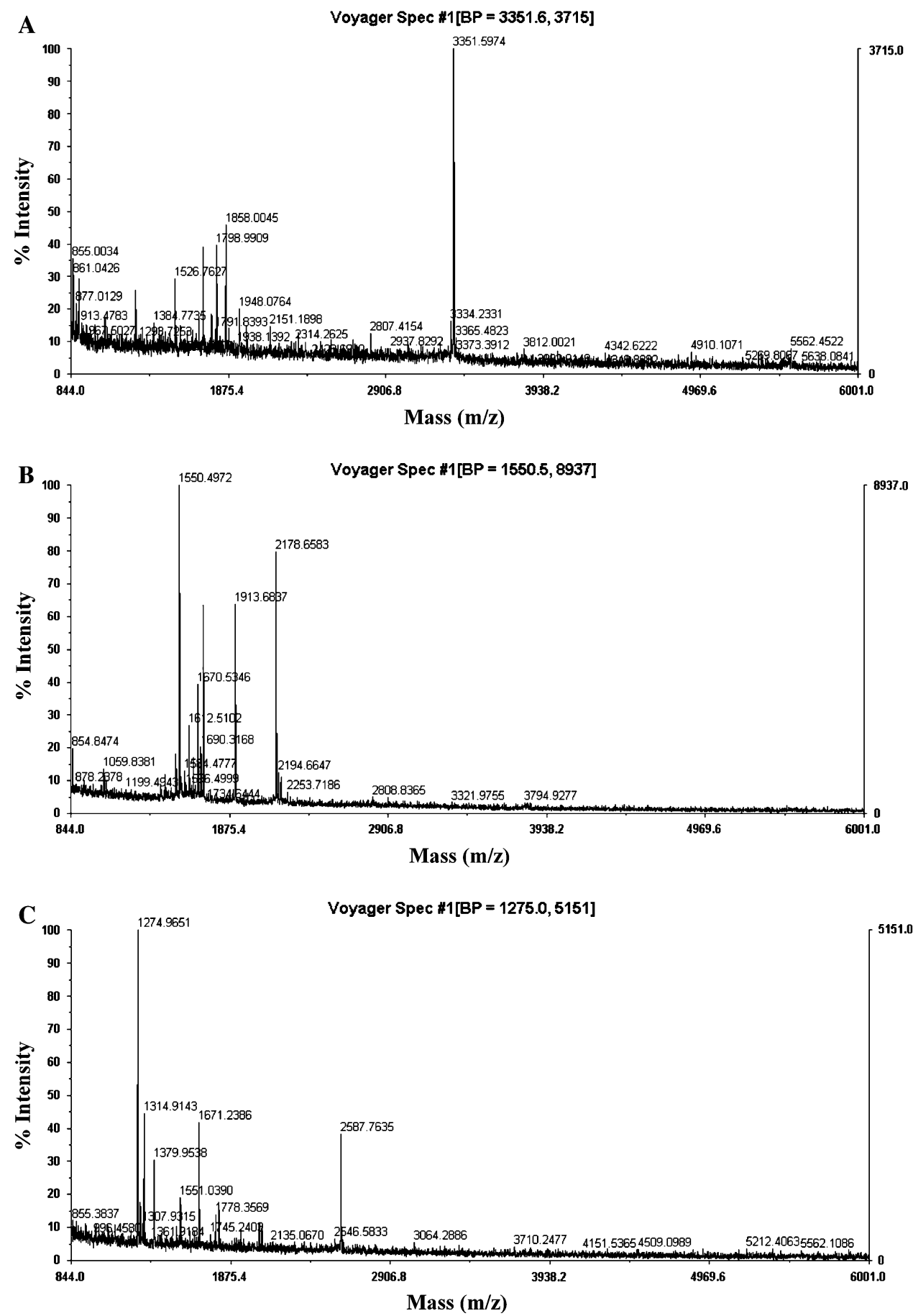

we sonicated the diluted sera before the depletion and desalting steps as suggested by Quero et al. [32, 33]. The improvements we made in sample preparation enabled us to find some valuable low abundant proteins.

Of the 13 successfully identified protein spots, we focused on 10 up-regulated proteins in NPC for further validation. We also accumulated certain knowledge about three proteins by literature profiling. Finally, we decided to further investigate SICAM-1, HSP70 and SAA, which seemed more associated with our research interest, using both ELISA and IHC to validate their differential expressions. Intriguingly, most of these identified proteins have been reported to be associated with carcinogenesis and tumor metastasis. Our research is herein chiefly concerned with the functional implications of the three proteins to NPC at the serum level.

Although the source of sICAM-1 has not been fully elucidated, researches show it can be released by cancer 


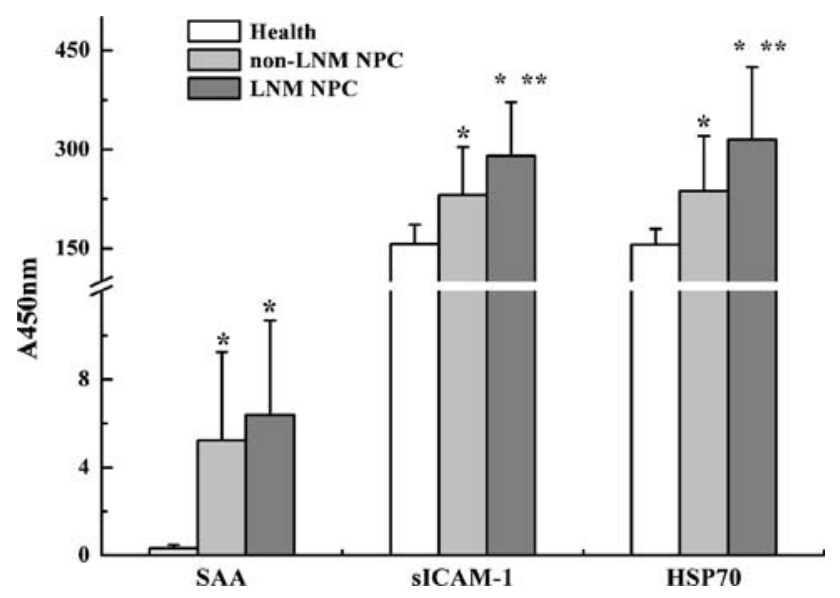

Fig. 4 Quantitative comparison of sICAM-1, HSP70 and SAA in sera among healthy, non-LNM NPC and LNM NPC groups. Each bar represents the mean \pm S.D. of the concentration, with significant differences between groups found by one-way ANOVA test. Note that this panel has a different vertical (y) axis and a break in the axis to accommodate the poor performance of the subject SAA. The break region is from 500 to $4500 \mu \mathrm{g} / \mathrm{l}$. $* P<0.05$, compared with healthy group; $* * P<0.05$, compared with non-LNM NPC group

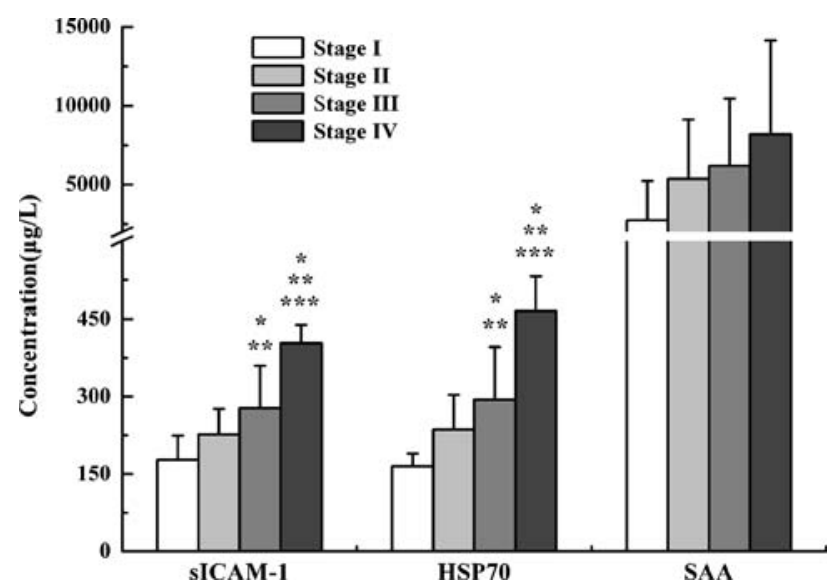

Fig. 5 Quantitative comparison of sICAM-1, HSP70 and SAA in sera among NPC patients at different TNM stage. Each bar represents the mean \pm S.D. of the concentration, with significant differences between groups found by one-way ANOVA test. Note that this panel has a different vertical (y) axis and a break in the axis to accommodate the poor performance of the subject SAA. The break region is from 600 to $2000 \mu \mathrm{g} / \mathrm{l}$. $* P<0.05$, compared with NPC patients at TNM stage I; $* * P<0.05$, compared with NPC patients at TNM stage II; $* * * P<0.05$, compared with NPC patients at TNM stage III

cells $[13,14]$ as well as by peripheral blood mononuclear, endothelial, and fibroblastic cells [34]. Proteolytic cleavage of membrane-bound ICAM-1 may be the most likely mechanism for the generation of sICAM-1 [35]. In patients with certain malignancies, the serum sICAM-1 titers have been found elevated in association with tumor growth and distant metastasis of malignant melanoma [36], lung [37], breast [38], gastric [39], hepatocellular [40], and colorectal cancers [41]. Poor survival of cancer patients correlated with a high level of serum sICAM-1 has also been demonstrated [36, 38, 39]. In our study, the positive expression of tissue ICAM-1 and levels of serum sICAM-1 were significantly correlated to the presence, progression, metastasis and mortality of NPC. sICAM-1 possesses most of the necessary extracellular structures to retain the functional activities of ICAM-1 [13, 35]. It has been reported that ICAM-1 on the surface of cancer cells or antigen presenting cells (i.e., macrophages) is a costimulatory factor that stabilizes T-cell receptor-mediated binding between these cells and $\mathrm{T}$ lymphocytes [42]. sICAM-1 would work as an immunosuppressive agent by blocking LFA-1 on T lymphocytes, thus rendering it less available for binding with ICAM-1 on the surface of cancer cells [43]. In this manner, the shedding of sICAM-1 may speed up the metastatic process by escaping host immune surveillance. This, probably, presents an additional potential mechanism accounting for high serum levels of sICAM-1 in NPC patients who have metastasized via hematogenous and lymphatic routes. As serum sICAM-1 may be useful for monitoring hematogenous metastasis, measuring the serum sICAM-1 level might be potentially significant in clinic.

SAA is an acute-phase protein with various isoforms in a molecular mass range of 11-14. In normal individuals, SAA is produced by hepatocytes in the liver [16]. After secreted into serum, it rapidly binds to high-density lipoprotein, with $90 \%$ of the protein particles bound [15]. A review of the literature shows that only a low level of SAA can be found in the sera of healthy individuals, despite the ubiquitous nature of SAA [44]. This is in sharp contrast to the patients with neoplastic diseases, such as those with renal [45] and colorectal [46] cancers, who showed dramatic elevation of serum SAA. The prognostic significance of SAA for other cancers has also been found by conventional radioimmunoassay, in line with the findings of this study [47]. Cho et al. demonstrated that SAA may be a potentially usefully biomarker for NPC [24]. The report fully confirmed relatively huge concentrations of SAA in serum $(0.2-2 \mathrm{~g} / \mathrm{l})$ that are thousands of times higher than classical cancer biomarkers (such as CEA, PSA, CA125, etc.) originating from tumor cells. In a similar way, we further confirmed that serum SAA was much elevated in NPC patients, particularly at the process of lymph node metastases when compared with non-LNM patients. However, such biomarkers (acute-phase reactants) are not commonly considered as cancer-specific ones and expected to be elevated in other malignant diseases or inflammatory diseases as well [26, 27]. In previous reports, SAA was found elevated in different malignancies, such as cancers of kidney, colon and prostate, as well as in leukemias and 


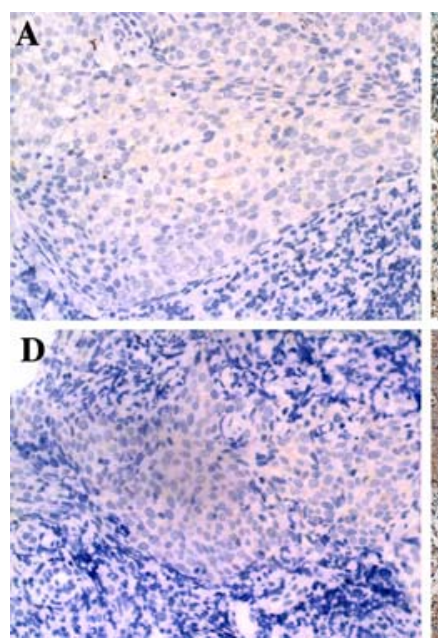

Fig. 6 Immunohistochemical detection of HSP70 and ICAM-1 in NPC (Magnification $\times 200$ ). The immunoreactivity was located in both membrane and cytoplasmic stainings for ICAM-1 but only in cytoplasmic staining for HSP70. The black arrows indicate the target proteins stained in brown-yellow in the NPC nest. The red arrow in E

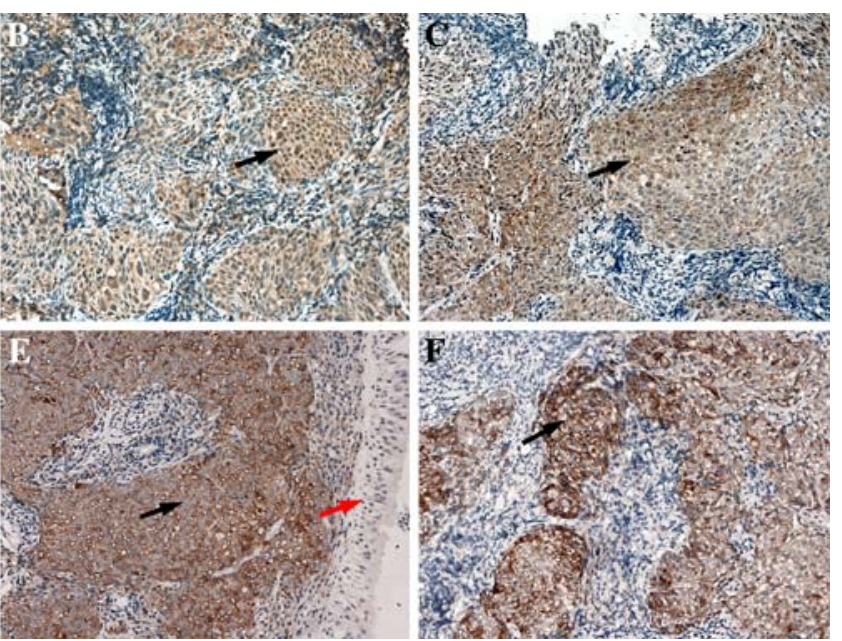

shows negative immunoreactivity of normal nasopharyngeal epithelia. a, negative expression of HSP70; b and c, positive expressions of HSP70; d, negative expression of ICAM-1; e and $\mathbf{f}$, positive expressions of ICAM-1; $\mathbf{a}, \mathbf{b}, \mathbf{d}$ and $\mathbf{e}$, non-LNM NPC; $\mathrm{C}$ and $\mathrm{F}$, LNM NPC

Table 3 Characteristics of NPC patients dependent on ICAM-1 and HSP70 expressions

\begin{tabular}{|c|c|c|c|c|c|c|c|}
\hline \multirow[t]{2}{*}{ Characteristics } & \multirow[t]{2}{*}{ Number } & \multicolumn{3}{|c|}{ ICAM-1 expression } & \multicolumn{3}{|c|}{ HSP70 expression } \\
\hline & & Negative & Positive (\%) & $P$ value & Negative & Positive (\%) & $P$ value \\
\hline \multicolumn{8}{|l|}{ Gender } \\
\hline Male & 41 & 9 & $32(78.0)$ & 0.464 & 15 & $26(63.4)$ & 0.704 \\
\hline Female & 16 & 5 & $11(68.8)$ & & 5 & $11(68.8)$ & \\
\hline \multicolumn{8}{|l|}{ Age } \\
\hline \multicolumn{8}{|l|}{ Mean (45.4) } \\
\hline$<45$ years & 26 & 7 & $19(73.1)$ & 0.704 & 9 & $17(65.4)$ & 0.945 \\
\hline$\geq 45$ years & 31 & 7 & $24(77.4)$ & & 11 & $20(64.5)$ & \\
\hline \multicolumn{8}{|c|}{ Lymph node status } \\
\hline Positive & 30 & 3 & $27(90.0)$ & 0.012 & 5 & $25(83.3)$ & 0.002 \\
\hline Negative & 27 & 11 & $16(59.3)$ & & 15 & $12(44.4)$ & \\
\hline \multicolumn{8}{|l|}{ TNM stage } \\
\hline $\mathrm{I}+\mathrm{II}$ & 24 & 11 & $13(54.2)$ & 0.002 & 12 & $12(50.0)$ & 0.044 \\
\hline $\mathrm{III}+\mathrm{IV}$ & 33 & 3 & $30(90.9)$ & & 8 & $25(75.8)$ & \\
\hline \multicolumn{8}{|l|}{ Survival rate } \\
\hline Survival & 20 & 6 & $14(70)$ & 0.280 & 6 & $14(70)$ & 1.000 \\
\hline Mortality & 6 & 0 & $6(100)$ & & 1 & $5(83.3)$ & \\
\hline
\end{tabular}

Note: Values in parentheses are percentages

lymphomas [24, 48]. Therefore, SAA may represent a cancer epiphenomenon, unlikely to be of much clinical use in diagnosing and monitoring cancer [49], but it will be interesting to explore whether the rapid production of SAA in the liver or the epithelia of different organs [50] may be related to the stimulation by cytokines abundantly present in the NPC cells. It is also meaningful to investigate how
SAA is produced at different stages of clinical manifestation in NPC patients.

HSP70 is the main protein produced during cellular response to varied stresses, such as heat shock, ischemia/ reperfusion, and oxidative changes [51, 52]. Because HSP70 confers cell protection against different stresses, it has been hypothesized that it plays a protective role in 
tumor growth in vivo $[53,54]$. Indeed, HSP70 is overexpressed in human tumors of varied origins [55], such as colorectal [56], breast [57, 58], prostate [59], liver [60] cancers and melanoma [61]. LNM and poor survival of cancer patients correlated with HSP70 overexpression has also been documented [57, 58, 61-63]. It is suggested that HSP70 is needed for in vivo tumor progression. In addition, HSP70 may be released from tumor cells involving involves both active secretion and passive release from necrotic cells [64]. Physiological mechanisms include cosecretion in exosomes of HSC70 with TRF and the active HSP70 secretion by the nonclassical pathway employed by cytokines [65]. Therefore, HSP70 is detectable in serum so that it could potentially be used as a biomarker for diagnosis or disease classification. Abe et al. reported that HSP70 is a marker of prostate cancer, and may be used in conjunction with PSA to identify patients with early-stage prostate cancer [59]. However, to the best of our knowledge, the association between serum level of HSP70 and NPC status has not been reported. Since our findings demonstrated that there was a modest association between serum HSP70 level and NPC staging, the serum HSP70 level should not be considered as an independent prognostic factor in NPC patients, although it might be a prognostic predictor by univariate analysis. In short, serum HSP70 may have an adjunctive clinical value in monitoring tumor progression and evaluating prognosis in NPC patients, though its clinical application as a major tumor marker is limited.

In conclusion, our serum proteomic analysis, using a comprehensive pretreatment strategy, provides a practical and exemplary tool of screening progression-associated serum proteins in NPC research. After comparing 2D image analyses for healthy volunteers, non-LNM NPC and LNM NPC patients, we successfully identified 13 differentially expressed protein spots. We further explored the differential expressions of three of the proteins, namely, sICAM-1, HSP70 and SAA, by ELISA at serum and IHC at tissue, though more work should be completed to pinpoint the direct correlation between serum level of sICAM and HSP70 and their expression level in the tissues. We suggest that the three proteins may be potential serum biomarkers which can serve as effective target points for early diagnosis and therapy of NPC patients, though further clinical research should be done before the potential come true.

Acknowledgment This work was financially supported by National Key Basic Research Program of China (973 Program) (No. 2001CB510207), Key Science and Technology Research Program of Guangdong Province (No. 2003A308401) and Natural Science Foundation of Guangdong Province (No. 5200512). We also thank Professor Liang Ping for his critical reading and revision of the manuscript.
Open Access This article is distributed under the terms of the Creative Commons Attribution Noncommercial License which permits any noncommercial use, distribution, and reproduction in any medium, provided the original author(s) and source are credited.

\section{References}

1. Kumar S, Mahanta J (1998) Aetiology of nasopharyngeal carcinoma. A review. Indian J Cancer 35(2):47-56

2. Yu MC, Yuan JM (2002) Epidemiology of nasopharyngeal carcinoma. Semin Cancer Biol 12(6):421-429

3. Yang HY, Xiao ZQ, Li F (2004) Establishment of 2-dE map of human low differentiation nasopharyngeal carcinoma cell line CNE-2 proteome. Zhong Nan Da Xue Xue Bao Yi Xue Ban 29(2):123-128

4. Jiang P, Gan M, Huang $\mathrm{H}$ et al (2005) Proteome analysis of antiproliferative mechanism of 12-O-tetradecanoylphorbol 13-acetate on cultured nasopharyngeal carcinoma CNE2 cells. J Proteome Res 4(2):599-605

5. Li F, Xiao Z, Zhang P et al (2007) A reference map of human nasopharyngeal squamous carcinoma proteome. Int $\mathrm{J}$ Oncol 30(5): 1077-1088

6. Tan C, Li J, Wang J et al (2002) Proteomic analysis of differential protein expression in human nasopharyngeal carcinoma cells induced by NAG7 transfection. Proteomics 2(3):306-312

7. Sun Y, Yi H, Zhang PF et al (2007) Identification of differential proteins in nasopharyngeal carcinoma cells with p53 silence by proteome analysis. FEBS Lett 581(1):131-139

8. Sun D, Zhang Z, Van do N et al (2007) Aberrant methylation of CDH13 gene in nasopharyngeal carcinoma could serve as a potential diagnostic biomarker. Oral Oncol 43(1):82-87

9. Doustjalali SR, Yusof R, Govindasamy GK et al (2006) Patients with nasopharyngeal carcinoma demonstrate enhanced serum and tissue ceruloplasmin expression. J Med Invest 53(1-2):20-28

10. Weinkauf M, Hiddemann W, Dreyling M (2006) Sample pooling in 2-D gel electrophoresis: a new approach to reduce nonspecific expression background. Electrophoresis 27(22):4555-4558

11. Ramagli LS (1999) Quantifying protein in 2-D PAGE solubilization buffers. Methods Mol Biol 112:99-103

12. Yan JX, Wait R, Berkelman T et al (2000) A modified silver staining protocol for visualization of proteins compatible with matrix-assisted laser desorption/ionization and electrospray ionization-mass spectrometry. Electrophoresis 21(17):3666-3672

13. Jackson AM, Alexandrov AB, Gribben SC et al (1993) Expression and shedding of ICAM-1 in bladder cancer and its immunotherapy. Int J Cancer 55(6):921-925

14. Santarosa M, Favaro D, Quaia M et al (1995) Expression and release of intercellular adhesion molecule-1 in renal-cancer patients. Int J Cancer 62(3):271-275

15. Bausserman LL, Herbert PN, Rodger R et al (1984) Rapid clearance of serum amyloid A from high-density lipoproteins. Biochim Biophys Acta 792(2):186-191

16. Raynes JG, Eagling S, McAdam KP (1991) Acute-phase protein synthesis in human hepatoma cells: differential regulation of serum amyloid A (SAA) and haptoglobin by interleukin-1 and interleukin-6. Clin Exp Immunol 83(3):488-491

17. Hunt SM, Thomas MR, Sebastian LT et al (2005) Optimal replication and the importance of experimental design for gel-based quantitative proteomics. J Proteome Res 4(3):809-819

18. Anderson NL, Anderson NG (2002) The human plasma proteome: history, character, and diagnostic prospects. Mol Cell Proteomics 1(11):845-867 
19. Etzioni R, Urban N, Ramsey S et al (2003) The case for early detection. Nat Rev Cancer 3(4):243-252

20. Zhang H, Liu AY, Loriaux P et al (2007) Mass spectrometric detection of tissue proteins in plasma. Mol Cell Proteomics 6(1):64-71

21. Anderson NL, Polanski M, Pieper R et al (2004) The human plasma proteome: a nonredundant list developed by combination of four separate sources. Mol Cell Proteomics 3(4):311-326

22. Thadikkaran L, Siegenthaler MA, Crettaz D et al (2005) Recent advances in blood-related proteomics. Proteomics 5(12):30193034

23. Nedelkov D, Kiernan UA, Niederkofler EE et al (2005) Investigating diversity in human plasma proteins. Proc Natl Acad Sci USA 102(31):10852-10857

24. Cho WC, Yip TT, Yip C et al (2004) Identification of serum amyloid a protein as a potentially useful biomarker to monitor relapse of nasopharyngeal cancer by serum proteomic profiling. Clin Cancer Res 10(1 Pt 1):43-52

25. Diamandis EP (2003) Point: proteomic patterns in biological fluids: do they represent the future of cancer diagnostics? Clin Chem 49(8):1272-1275

26. Diamandis EP (2004) Analysis of serum proteomic patterns for early cancer diagnosis: drawing attention to potential problems. J Natl Cancer Inst 96(5):353-356

27. Diamandis EP (2004) Mass spectrometry as a diagnostic and a cancer biomarker discovery tool: opportunities and potential limitations. Mol Cell Proteomics 3(4):367-378

28. Putnam RW (1975) The plasma proteins. New York Academic Press

29. Curry S (2002) Beyond expansion: structural studies on the transport roles of human serum albumin. Vox Sang 83(Suppl 1):315-319

30. Dea MK, Hamilton-Wessler M, Ader M et al (2002) Albumin binding of acylated insulin (NN304) does not deter action to stimulate glucose uptake. Diabetes 51(3):762-769

31. Schussler GC (2000) The thyroxine-binding proteins. Thyroid 10(2):141-149

32. Quero C, Colome N, Prieto MR et al (2004) Determination of protein markers in human serum: analysis of protein expression in toxic oil syndrome studies. Proteomics 4(2):303-315

33. Feng JT, Liu YK, Song HY et al (2005) Heat-shock protein 27: a potential biomarker for hepatocellular carcinoma identified by serum proteome analysis. Proteomics 5(17):4581-4588

34. Rothlein R, Mainolfi EA, Czajkowski M et al (1991) A form of circulating ICAM-1 in human serum. J Immunol 147(11):37883793

35. Budnik A, Grewe M, Gyufko K et al (1996) Analysis of the production of soluble ICAM-1 molecules by human cells. Exp Hematol 24(2):352-359

36. Harning R, Mainolfi E, Bystryn JC et al (1991) Serum levels of circulating intercellular adhesion molecule 1 in human malignant melanoma. Cancer Res 51(18):5003-5005

37. Grothey A, Heistermann P, Philippou S et al (1998) Serum levels of soluble intercellular adhesion molecule-1 (ICAM-1, CD54) in patients with non-small-cell lung cancer: correlation with histological expression of ICAM-1 and tumour stage. Br J Cancer 77(5):801-807

38. Zhang GJ, Adachi I (1999) Serum levels of soluble intercellular adhesion molecule-1 and E-selectin in metastatic breast carcinoma: correlations with clinicopathological features and prognosis. Int J Oncol 14(1):71-77

39. Nakata B, Hori T, Sunami T et al (2006) Clinical significance of serum soluble intercellular adhesion molecule 1 in gastric cancer. Clin Cancer Res 6(3):1175-1179

40. Shimizu Y, Minemura M, Tsukishiro T et al (1995) Serum concentration of intercellular adhesion molecule-1 in patients with hepatocellular carcinoma is a marker of the disease progression and prognosis. Hepatology 22(2):525-531

41. Kitagawa T, Matsumoto K, Iriyama K (1998) Serum cell adhesion molecules in patients with colorectal cancer. Surg Today 28(3):262-267

42. Yoo NC, Chung HC, Chung HC et al (1998) Synchronous elevation of soluble intercellular adhesion molecule-1 (ICAM-1) and vascular cell adhesion molecule-1 (VCAM-1) correlates with gastric cancer progression. Yonsei Med J 39(1):27-36

43. Becker JC, Termeer C, Schmidt RE et al (1993) Soluble intercellular adhesion molecule-1 inhibits MHC-restricted specific T cell/tumor interaction. J Immunol 151(12):7224-7232

44. d'Eril GM, Anesi A, Maggiore M et al (2001) Biological variation of serum amyloid $\mathrm{A}$ in healthy subjects. Clin Chem 47(8):1498-1499

45. Kimura M, Tomita Y, Imai T et al (2001) Significance of serum amyloid $\mathrm{A}$ on the prognosis in patients with renal cell carcinoma. Cancer 92(8):2072-2075

46. Glojnaric I, Casl MT, Simic D et al (2001) Serum amyloid A protein (SAA) in colorectal carcinoma. Clin Chem Lab Med 39(2):129-133

47. Biran H, Friedman N, Neumann L et al (1986) Serum amyloid A (SAA) variations in patients with cancer: correlation with disease activity, stage, primary site, and prognosis. J Clin Pathol 39(7):794-797

48. Benson MD, Cohen AS (1979) Serum amyloid A protein in amyloidosis, rheumatic, and enoplastic diseases. Arthritis Rheum 22(1):36-42

49. Diamandis EP (2004) Identification of serum amyloid a protein as a potentially useful biomarker for nasopharyngeal carcinoma. Clin Cancer Res 10(15):5293; author reply-4

50. Urieli-Shoval S, Cohen P, Eisenberg S et al (1998) Widespread expression of serum amyloid A in histologically normal human tissues. Predominant localization to the epithelium. J Histochem Cytochem 46(12):1377-1384

51. Lindquist S (1986) The heat-shock response. Annu Rev Biochem 55:1151-1191

52. Subjeck JR, Shyy TT (1986) Stress protein systems of mammalian cells. Am J Physiol 250(1 Pt 1):C1-C17

53. Barnes JA, Dix DJ, Collins BW et al (2001) Expression of inducible Hsp70 enhances the proliferation of MCF-7 breast cancer cells and protects against the cytotoxic effects of hyperthermia. Cell Stress Chaperones 6(4):316-325

54. Ravagnan L, Gurbuxani S, Susin SA et al (2001) Heat-shock protein 70 antagonizes apoptosis-inducing factor. Nat Cell Biol 3(9):839-843

55. Clark PR, Menoret A (2001) The inducible Hsp70 as a marker of tumor immunogenicity. Cell Stress Chaperones 6(2):121-125

56. Milicevic ZT, Petkovic MZ, Drndarevic NC et al (2007) Expression of heat shock protein 70 (HSP70) in patients with colorectal adenocarcinoma-immunohistochemistry and Western blot analysis. Neoplasma 54(1):37-45

57. Lazaris A, Chatzigianni EB, Panoussopoulos D et al (1997) Proliferating cell nuclear antigen and heat shock protein 70 immunolocalization in invasive ductal breast cancer not otherwise specified. Breast Cancer Res Treat 43(1):43-51

58. Torronteguy C, Frasson A, Zerwes F et al (2006) Inducible heat shock protein 70 expression as a potential predictive marker of metastasis in breast tumors. Cell Stress Chaperones 11(1):34-43

59. Abe M, Manola JB, Oh WK et al (2004) Plasma levels of heat shock protein 70 in patients with prostate cancer: a potential biomarker for prostate cancer. Clin Prostate Cancer 3(1): 49-53

60. Chuma M, Sakamoto M, Yamazaki K et al (2003) Expression profiling in multistage hepatocarcinogenesis: identification of 
HSP70 as a molecular marker of early hepatocellular carcinoma. Hepatology 37(1):198-207

61. Lazaris AC, Theodoropoulos GE, Aroni K et al (1995) Immunohistochemical expression of C-myc oncogene, heat shock protein 70 and HLA-DR molecules in malignant cutaneous melanoma. Virchows Arch 426(5):461-467

62. Kaur J, Das SN, Srivastava A et al (1998) Cell surface expression of $70 \mathrm{kDa}$ heat shock protein in human oral dysplasia and squamous cell carcinoma: correlation with clinicopathological features. Oral Oncol 34(2):93-98
63. Volm M, Koomagi R, Mattern J et al (2002) Protein expression profile of primary human squamous cell lung carcinomas indicative of the incidence of metastases. Clin Exp Metastasis 19(5):385-390

64. Mambula SS, Calderwood SK (2006) Heat induced release of Hsp70 from prostate carcinoma cells involves both active secretion and passive release from necrotic cells. Int J Hyperthermia 22(7):575-585

65. Mambula SS, Calderwood SK (2006) Heat shock protein 70 is secreted from tumor cells by a nonclassical pathway involving lysosomal endosomes. J Immunol 177(11):7849-7857 